\title{
Early-onset epileptic encephalopathy and intellectual disability due to GRIN2A mutation
}

INSERM

\section{Source}

INSERM. (1999). Orphanet: an online rare disease and orphan drug data base. Early-onset epileptic encephalopathy and intellectual disability due to GRIN2A mutation.

ORPHA:289266

Early-onset epileptic encephalopathy and intellectual disability due to GRIN2A mutation is a rare intellectual disability and epilepsy syndrome characterized by global developmental delay and mild to profound intellectual disability, multiple types of usually intractable focal and generalized seizures with variable abnormal EEG findings, and bilateral prog ressive parenchymal volume loss and thin corpus callosum on brain MRI. 